\section{RAPD Markers from Perennial Ryegrass DNA Extracted from Seeds}

\author{
Patricia M. Sweeney and T. Karl Danneberger \\ Department of Horticulture and Crop Science, The Ohio State University, \\ Columbus, $\mathrm{OH} 43210$
}

Additional index words. arbitrarily primed PCR, DNA fingerprinting, cultivar identification

\begin{abstract}
As the number of perennial ryegrass (Lolium perenne L.) cultivars increases, the development of reliable identification methods becomes more important. Randomly amplified polymorphic DNA (RAPD) markers show promise in cultivar identification. Since perennial ryegrass cultivars are composites of genotypes rather than a single genotype, finding markers that distinguish cultivars is difficult. The ideal cultivar identification procedure would use seed tissue as a DNA source and evaluate a single sample as representative of a cultivar. The objective of this research was to determine whether RAPD markers could be used to consistently distinguish bulk seed samples of perennial ryegrass cultivars. Two extraction protocols were evaluated. A quick, simple extraction resulted in the amplification of few consistent RAPD markers. The more labor-intensive extraction with hexadecyltrimethyl ammonium bromide (CTAB), however, produced more reliable RAPD markers. Eight of 11 cultivars were distinguished by using RAPD markers produced using bulk seed samples together with four of 30 primers that were screened. These results show the potential of RAPD markers to provide the turfgrass industry, breeders, and certification agencies additional options to ensure the genetic integrity of perennial ryegrass seed lots and cultivars.
\end{abstract}

As the number of perennial ryegrass (Lolium perenne L.) cultivars increases, reliable methods must be developed to identify them. In the past, few markers were available for use in cultivar identification. Various laboratory methods, including sodium dodecylsulfate polyacrylamide gel electrophoresis of seed proteins (Ferguson and Grabe 1986; Gardiner et al., 1986), detection of isozymes via starch gel electrophoresis (Gilliland et al., 1982; Kennedy et al., 1985; Nielson et al., 1985; Ostergaard et al., 1985), and electrofocusing of seed proteins (de Prins and Van de Weghe, 1983), have been used successfully to characterize perennial ryegrass cultivars. These procedures, though useful, are sometimes limited by the number of variable seed proteins or isozymes available, the amount of tissue required for each analysis, and the possibility that storage or growth stage could affect the results of the assays. Williams et al. (1990) have described RAPD markers that could be

Received for publication $28 \mathrm{Jan}$. 1997. Accepted for publication 9 May 1997. Salaries and research support by State and Federal Funds appropriated to the Ohio Agriculture Research and Development Center, The Ohio State Univ. Manuscript no. 56-97. Additional support provided by the Ohio Turfgrass Foundation. Mention of a trademark, proprietary product, or vendor does not constitute a guarantee or warranty of the product by the Ohio State Univ. and does not imply its approval to the exclusion of other product or vendors that also may be suitable. The authors thank Loft Seed Co., Seed Research of Oregon, and Jacklin Seed Co. for providing seed of the cultivars used in the study. The cost of publishing this paper was defrayed in part by the payment of page charges. Under postal regulations, this paper therefore must be hereby marked advertisement solely to indicate this fact. used in conjunction with isozyme analysis to enhance cultivar identification in perennial ryegrass.

Finding markers that distinguish perennial ryegrass cultivars is difficult since they are synthetic cultivars and represent composites of genotypes. Two approaches are possible. The first uses RAPD markers amplified separately from numerous individuals of each cultivar (Huff, 1997). This approach is especially useful when relatedness of cultivars is of interest, but is too laborious for identification of cultivars on a routine basis.

The second approach uses one composite or bulk sample of the individuals from a synthetic cultivar. Results are expressed as differences between composite amplifications. Sweeney and Danneberger (1994) distinguished composite samples of two unrelated perennial ryegrass cultivars on the basis of one RAPD marker. This approach gives less information on the relatedness of the cultivars but, since it requires the amplification of fewer samples, is adaptable for routine cultivar identification.

These studies used leaf tissue for amplification. The use of seed for DNA extraction is preferred because it eliminates the need to grow out leaf tissue, thereby hastening the analysis. Perennial ryegrass seed DNA has been successfully used for amplification (Sweeney et al., 1996), but the reliability of RAPD markers generated by different primers and the ease of finding RAPD markers that distinguish bulk samples of perennial ryegrass has not been determined.

After screening 50 oligonucleotide primers, Golembiewski et al. (1997) found eight primers that identified 11 of 13 creeping bentgrass [Agrostis stolonifera $\mathbf{L}$. var.palustrus (Huds.) Farw.] cultivars based on composite seed samples. This research suggests that RAPD markers generated from DNA extracted from composite seed samples of perennial ryegrass may be reliable and useful in identification of perennial ryegrass cultivars.

For RAPD markers to be used routinely in cultivar identification, the procedure must be rapid as well as reliable. From a technology perspective, DNA quantification is one of the most time-consuming requirements and its elimination would speed cultivar identification.

The objectives of our research were to 1) evaluate the reliability of RAPD markers generated using two extraction protocols; 2) address the importance of DNA quantification for reliable amplification of RAPD markers; and 3) evaluate the potential of RAPD markers for identification of bulk seed samples of perennial ryegrass cultivars.

\section{Materials and Methods}

Seed of 11 cultivars of perennial ryegrass, 'Prelude II', 'Yorktown III', 'Palmer II', 'Repell II' (Lofts Seed Co., Bound Brook, N.J.), 'SR 4000', 'SR 4010', 'SR 4300', 'SR 4400', 'Omni' (Seed Research of Oregon, Corvallis, Ore.), 'Dandy', and 'Advent' (Jacklin Seed Co., Post Falls, Idaho) were used in the study.

Two methods were used for DNA extraction. The first was a modification of the Edwards et al. (1991) protocol, which will be termed "QUICK." After scarification and chaff removal, seed samples $(200 \mathrm{mg})$ were crushed with a metal rod and a buffer containing 200 mM Tris (pH 7.5), $290 \mathrm{mM} \mathrm{NaCl}, 25 \mathrm{mM}$ EDTA, and 17.3 mM SDS was added. Samples were centrifuged at $15,600 g_{\mathrm{n}}$ for $4 \mathrm{~min}$ prior to precipitation of DNA from the supernatant with absolute isopropanol. After centrifugation at $15,600 \mathrm{~g}_{\mathrm{n}}$ for $7 \mathrm{~min}$, the remaining pellets were dried, then resuspended in $10 \mathrm{mM}$ TrisHCl (pH 7.5) containing $1 \mathrm{mM}$ EDTA (TE). To ensure that results were repeatable, replicate extractions were made for each cultivar using the QUICK protocol.

The second extraction protocol was described by Saghai-Maroof et al. (1984) and will be termed "CTAB." After grinding $8 \mathrm{~g}$ of seed in a mechanical mill for $1 \mathrm{~min}, 2 \mathrm{~g}$ were placed in $9 \mathrm{~mL}$ buffer consisting of $27.4 \mathrm{mM}$ hexadecyltrimethyl ammonium bromide (CTAB), $14.3 \mathrm{mM}$ B-mercaptoethanol, 100 mM Tris (pH 7.5), $0.7 \mathrm{M} \mathrm{NaCl}$, and $10 \mathrm{mM}$ EDTA and incubated for $1 \mathrm{~h}$ at $65^{\circ} \mathrm{C}$. After cooling, chloroform/octanol $(24: 1, \mathrm{v} / \mathrm{v})$ was added and the samples were inverted. After centrifugation for $10 \mathrm{~min}$ at $5900 \mathrm{~g}_{\mathrm{n}}$, DNA was precipitated from the aqueous phase with $a b-$ solute isopropanol. A bent glass Pasteur pipet was used to remove the DNA. The DNA was washed for $20 \mathrm{~min}$ in $76 \%$ ethanol and $0.2 \mathrm{M}$ $\mathrm{NaC}_{2} \mathrm{H}_{3} \mathrm{O}_{2}$, then washed for $5 \mathrm{~min}$ in $76 \%$ ethanol and $10 \mathrm{mM} \mathrm{NH}_{4} \mathrm{C}_{2} \mathrm{H}_{3} \mathrm{O}_{2}$ before being dissolved in TE. Replicate CTAB extractions were made for each cultivar.

Samples from both extraction protocols were quantified using a TKO 100 Mini-Fluorometer (Hoefer Scientific Instruments, San 
Francisco, Calif.) then diluted to $3 \mu \mathrm{g} \cdot \mathrm{mL}^{-1}$ with TE. The CTAB samples were diluted 1:100 with TE for the second part of the experiment.

Thirty primers from a set of 100 decamers supplied by J.E. Carlson, Univ. of British Columbia, were screened using QUICK-extracted DNA. Eleven primers that produced numerous RAPD markers were rescreened using CTAB-extracted DNA. The $25-\mu \mathrm{L}$ amplification mixture contained $20 \mathrm{mM}$ Tris$\mathrm{HCl}, \mathrm{pH} 8.3,50 \mathrm{mM} \mathrm{KCl}, 3.0 \mathrm{mM} \mathrm{MgCl}_{2}, 0.2$ $\mu \mathrm{M}$ primer, $0.2 \mathrm{mM}$ each dATP, dGTP, dCTP, and dTTP, 1.5 units of DNA polymerase from Thermus aquaticus (TAQ DNA Polymerase, GIBCO BRL, Grand Island, N.Y.), and 0.75 to 9.6 ng DNA template. After a 3-min incubation at $94^{\circ} \mathrm{C}$, amplification was performed in a Thermocycler (Perkin-Elmer, Norwalk, Conn.) programmed for 40 cycles of $1 \mathrm{~min}$ at $94^{\circ} \mathrm{C}, 1 \mathrm{~min}$ at $40^{\circ} \mathrm{C}$, and $1 \mathrm{~min}$ at $72^{\circ} \mathrm{C}$. A 15 min extension period at $72{ }^{\circ} \mathrm{C}$ followed the amplification.

Gels containing $1.5 \%(\mathrm{~m} / \mathrm{v})$ agarose, 0.4 $\mathrm{mg} \cdot \mathrm{L}^{-1}$ ethidium bromide and TBE $(89 \mathrm{mM}$ Tris- $\mathrm{HCl}, \mathrm{pH} 8.3,89 \mathrm{mM}$ boric acid, $2 \mathrm{mM}$ EDTA) were used to separate amplification products. A mixture $(14 \mu \mathrm{L})$ containing the amplified sample plus $4 \mu \mathrm{L}$ of sample buffer IV $[0.25 \%(\mathrm{~m} / \mathrm{v})$ bromophenol blue, $40 \%(\mathrm{~m} /$ v) sucrose] (Sambrook et al., 1989) was loaded onto the gel for each reaction. Amplified DNA fragments were detected and photographed under ultraviolet light using a computer imaging system (FOTO/analyst, FOTODYNE, Hartland, Wis.). Amplifications were made for replicate extractions of the 11 cultivars to confirm results.

\section{Results and Discussion}

After screening 30 primers using the first replicate of the QUICK extraction, 11 primers that distinguished all 11 cultivars were found. To ensure repeatability of RAPD markers, these 11 primers were used to amplify replicate QUICK extractions of the same seed lot of each cultivar. When amplification was repeated, results were conflicting. Only 'Yorktown III', 'SR 4000', and 'Advent' had RAPD markers that were consistently amplified. In most cases, the RAPD marker that initially distinguished a cultivar was not amplified.

Observation of amplification results from the first extraction indicated that DNA from some cultivars routinely amplified better than others. For example, in screening the 30 primers using the first extraction, 'SR 4300' and 'Omni' had poor or virtually no amplification for 11 and 8 primers, respectively. For the other cultivars, the range was 1 to 4 . When the experiment was repeated on replicate extractions of the cultivars, 'SR 4300' was never amplified. In contrast, previous studies report consistent amplification using the QUICK protocol to extract DNA from perennial ryegrass leaf tissue (Sweeney and Danneberger, 1994). This implied that something unique to perennial ryegrass seed, especially this cultivar or seed lot, was present in the crude extract and was interfering with amplification of the DNA.

To continue the experiment we chose a second extraction protocol that included chloroform/octanol to separate the organic and aqueous phases and ethanol washes of the DNA after isopropanol precipitation. These additional steps should result in cleaner DNA. In addition, the CTAB extraction protocol required more seed tissue than the QUICK extraction. Thus, DNA concentrations resulting from $\mathrm{CTAB}$ extractions were higher ( 74 to $\left.960 \mu \mathrm{g} \cdot \mathrm{mL}^{-1}\right)$ than those from the QUICK extraction (14 to $\left.70 \mu \mathrm{g} \cdot \mathrm{mL}^{-1}\right)$. Dilutions ranging from $1: 25$ to $1: 300$ (vs. 1:4 to $1: 20$ for QUICK extraction) were made to reach the final concentration of $3 \mu \mathrm{g} \cdot \mathrm{mL}^{-1}$ desired for amplification. Thus, in addition to the protocol itself yielding cleaner DNA, any contaminant remaining in the final solution was diluted more than in the QUICK extraction protocol.

Eleven primers that produced RAPD markers in the screening of the QUICK-extracted DNA were rescreened using CTAB-extracted DNA. Eight of the 11 cultivars were distinguished using primers 203, 248, 250, and 268 (Table 1). For example, primer 203 produced a 1500-base pair (bp) doublet that distinguished 'SR 4400' (Fig. 1, lane 9) and a 950bp fragment that distinguished 'SR 4000' (Fig.
1, lane 7). 'SR 4000' was further distinguished by the lack of a 1500-bp fragment generated by primer 203 . Primer 250 produced a 1120 bp fragment that distinguished 'Omni' (Fig. 2, lane 8 ). The intensity of this 1120 -bp fragment, relative to the 1070-bp fragment below it, was much weaker for 'Omni' than for the other cultivars.

'Advent' could not be identified by a single primer, but could be identified by observing the amplification results of two primers. For example, the presence of a 720-bp fragment generated by primer 203 distinguished 'Yorktown III' and 'Advent' from the other cultivars, but not from each other (Fig. 1, lanes 2 and 11). Primers 209, 211, and 268 all produced fragments that identified 'Yorktown III'. Thus, primer 203 and either 209, 211, or 268 can be used to identify 'Advent'. Likewise, primer 250 produced a $1320-\mathrm{bp}$ fragment present only in 'Yorktown III' and 'Advent' (Fig. 2, lanes 2 and 11). Thus, primer 250 and primers 209,211 , or 268 can be used to identify 'Advent'.

Several cultivars could be distinguished by more than one primer. 'SR 4300', for example, could be distinguished by three primers. 'Prelude II', 'Palmer II', and 'SR 4010', however, could not be distinguished from each other

Table 1. Primers used to identify bulk samples of perennial ryegrass cultivars.

\begin{tabular}{ll}
\hline \hline Primer & \multicolumn{1}{c}{ Cultivars identified } \\
\hline 203 CACGGCGAGT & SR4000, SR4400, Advent* \\
209 TGCACTGGAG & Yorktown III, SR4300 \\
211 GAAGCGCGAT & Yorktown III \\
248 GAGTAAGCGG & Repell II, SR4300, SR4000, Advent* \\
250 CGACAGTCCC & Omni, Advent* \\
268 AGGCCGCTTA & Yorktown III, SR4300, Dandy \\
\hline
\end{tabular}

*Amplification with two primers needed for identification.

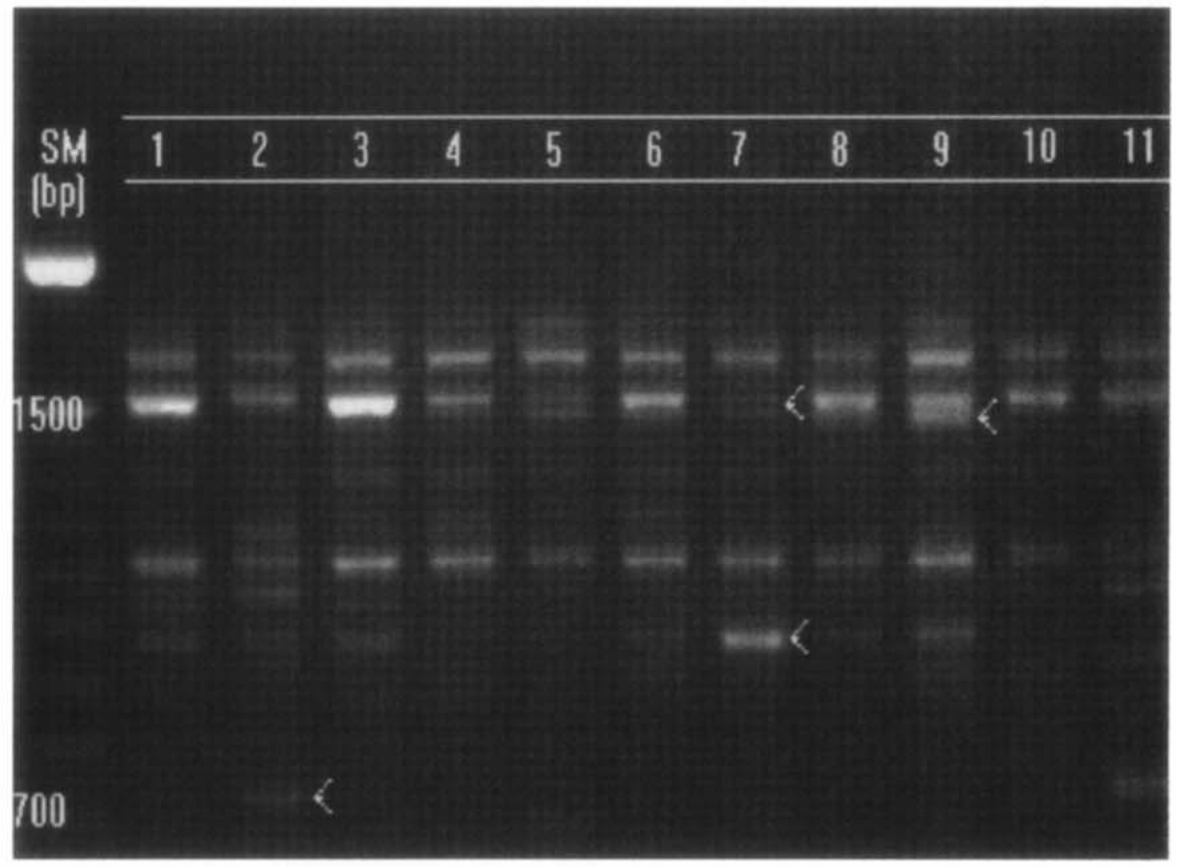

Fig. 1. RAPD markers in bulk seed samples of perennial ryegrass cultivars amplified using primer 203 and 3 ng CTAB-extracted DNA. Arrows indicate RAPD markers unique to particular cultivars. $1=$ Prelude II, 2 = Yorktown III, 3 = Palmer II, 4 = Repell II, $5=$ SR 4300, $6=$ SR 4010, 7 = SR 4000, $8=$ Omni, $9=\operatorname{SR} 4400,10=$ Dandy, $11=$ Advent. 


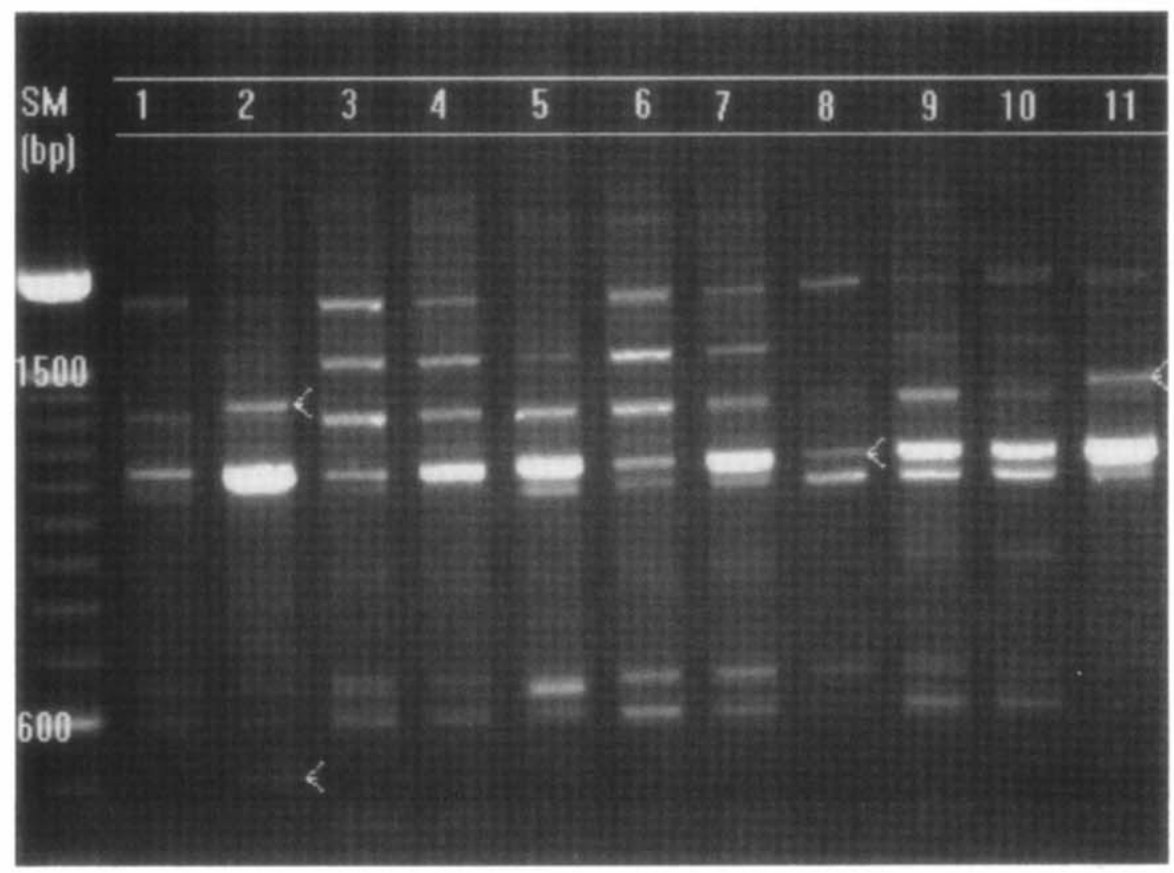

Fig. 2. RAPD markers in bulk seed samples of perennial ryegrass cultivars amplified using primer 250 and 3 ng CTAB-extracted DNA. Arrows indicate RAPD markers unique to particular cultivars. 1 = 'Prelude II', 2 = 'Yorktown III', 3 = 'Palmer II', 4 = 'Repell II', 5 = 'SR 4300', 6 = 'SR 4010', 7 = 'SR 4000', $8=$ 'Omn'i, 9 = 'SR 4400', 10 = 'Dandy', 11 = 'Advent'.

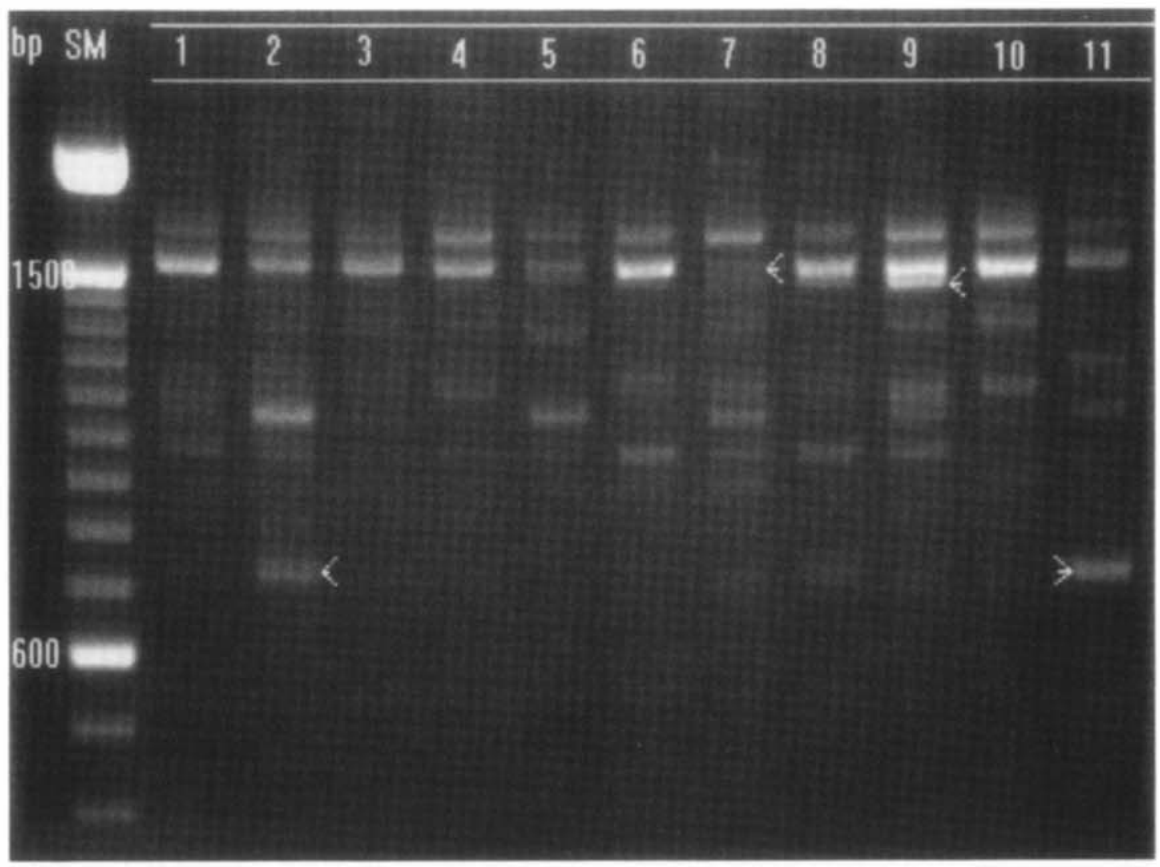

Fig. 3. RAPD markers in bulk seed samples of perennial ryegrass cultivars amplified using primer 203 and CTAB-extracted DNA that was diluted 1:100. Arrows indicate RAPD markers unique to particular cultivars. 1 = 'Prelude II', 2 = 'Yorktown III', 3 = 'Palmer II', 4 = 'Repell II', 5 = 'SR 4300', 6 = 'SR 4010', 7 = 'SR 4000', 8 = 'Omni', 9 = 'SR 4400', 10 = 'Dandy', 11 = 'Advent'.

with the primers we screened. Amplification of replicate $\mathrm{CTAB}$ extractions indicated that the results were repeatable. The CTAB extraction was the more labor-intensive of the two protocols, but in our studies it produced more reliable RAPD markers and therefore would be preferred for cultivar identification.

When CTAB-extracted samples were di- luted 1:100, 0.75 to $9.6 \mathrm{ng}$ DNA was used in each amplification reaction. By comparison, 3 ng DNA was used when the same samples were diluted to $3 \mu \mathrm{g} \cdot \mathrm{mL}^{-1}$ based on fluorometer readings. Although amplification banding patterns were not always identical (comcultivar that was identified using the $\mathrm{CTAB}$ pare Fig. 1 with 3 and Fig. 2 with 4 ), each extraction had at least one RAPD marker that reliably identified the cultivar regardless of the dilution method used. These results illustrate that some RAPD markers were not affected by differences in DNA concentration within the range generated using the CTAB extraction. Thus, standardization of DNA concentration is not necessarily needed for reliable cultivaridentification; nevertheless, some RAPD markers were affected by DNA concentration. If the goal is to omit DNA quantification in routine analyses, preliminary tests must be performed to verify that DNA concentrations fall within a range that provides reliable results for a given primer and RAPD marker. Reliable cultivar identification will require verification of this step and standardization of amplification protocols, including extraction procedures.

Amplification of DNA extracted using the CTAB protocol was superior to amplification using QUICK extraction. After screening 30 primers, eight of 11 cultivars were distinguished based on specific RAPD markers amplified from bulk seed samples. We conclude that perennial ryegrass cultivars can be differentiated based on RAPD markers generated using bulk samples of seed. Quantification of DNA was not always necessary to produce reliable RAPD markers for distinguishing cultivars. The necessity of quantifying DNA probably will be dependent on the range of concentrations that can be expected using a standard extraction protocol and the sensitivity of individual primers to variations in DNA concentration.

These results indicate that RAPD markers will be useful in distinguishing composite samples of perennial ryegrass, but more research will be needed to verify their use in routine cultivar identification. Many newer cultivars, including most of the cultivars used in our study, contain high levels of endophytes. Endophytic DNA could contribute to the RAPD marker banding pattern of cultivars. If levels of endophyte remain stable, this should not affect the use of RAPD markers in cultivar identification. As long as sample size is large enough to adequately sample endophytic DNA as well as the perennial ryegrass DNA, the endophytic DNA may be considered part of the cultivar's overall DNA profile. If, however, endophyte levels are reduced or lost, loss of endophytic RAPD markers could occur and change the banding profile. If reductions in endophyte levels are common, the RAPD markers used for cultivar identification must be shown to be reliable regardless of endophyte level.

\section{Literature Cited}

de Prins, H.C. and L. Van de Weghe. 1983. Ryegrass cultivar identification using electrofocusing on polyacrylamide gels. Seed Sci. Technol. 11:257-266.

Edwards, K., C. Johnstone, and C. Thompson. 1991. A simple and rapid method for the preparation of plant genomic DNA for PCR analysis. Nucleic Acids Res. 19:1349.

Ferguson, J.M. and D.F. Grabe. 1986. Identification of cultivars of perennial ryegrass by SDS-PAGE of seed protein. Crop Sci. 26:170-176.

Gardiner, S.E., M.B. Forde, and C.R. Slack. 1986. 


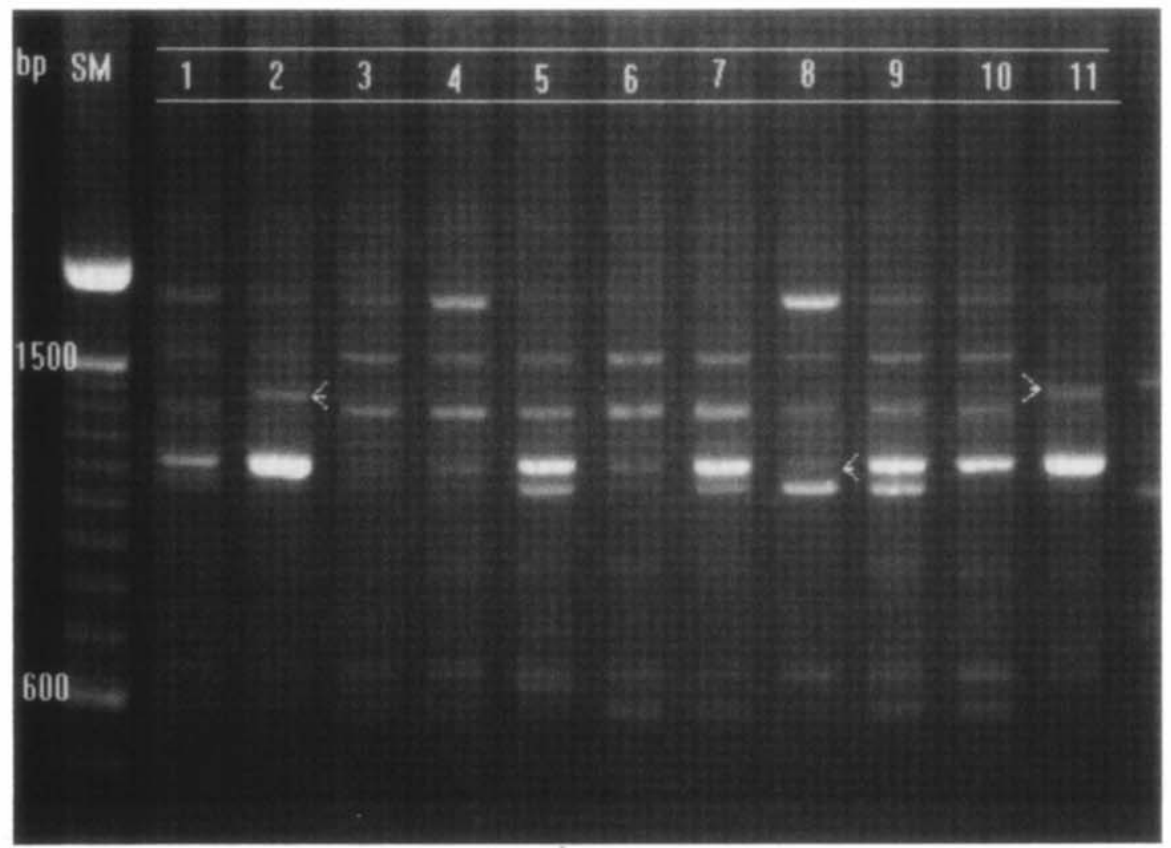

Fig. 4. RAPD markers in bulk seed samples of perennial ryegrass cultivars amplified using primer 250 and CTAB-extracted DNA that was diluted 1:100. Arrows indicate RAPD markers unique to particular cultivars. 1 = 'Prelude II', 2 = 'Yorktown III', 3 = 'Palmer II', 4 = 'Repell II', 5 = 'SR 4300', 6 = 'SR 4010 ', 7 = 'SR 4000', 8 = 'Omni', 9 = 'SR 4400', 10 = 'Dandy', 11 = 'Advent'.

Grass cultivar identification by sodium dodecylsulphate polyacrylamide gel electrophoresis. New Zealand J. Agr. Res. 29:193-206.

Gilliland, T.J., M.S. Camlin, and C.E. Wright. 1982

Evaluation of phosphoglucoisomerase allozyme electrophoresis for the identification and regis-
Huff, D.R. 1997. RAPD characterization of heterogeneous perennial ryegrass cultivars. Crop Sci. 37:557-564.

Kennedy, S.J., S.J. Gardiner, T.J. Gilliland, and M.S. Camlin. 1985. The use of electrophoretic techniques to distinguish perennial ryegrass cultivars when sown in mixtures. J. Agr. Sci. 104:1-

Nielsen, G., H. Ostergaard, and H. Johansen. 1985. Cultivar identification by means of isoenzymes. II. Genetic variation at four enzyme loci in diploid ryegrass. Z. Pflanzenzuchtg 94:74-86.

Ostergaard, H., G. Nielsen, and H. Johansen. 1985. Genetic variation in cultivars of diploid ryegrass, Lolium perenne and $L$. multiflorum, at five enzyme systems. Theor. Appl. Genet. 69:409421.

Saghai-Maroof, M.A., K.M. Soliman, R.A. Jorgensen, and R.W. Allard. 1984. Ribosomal DNA spacer-length polymorphisms in barley: Mendelian inheritance, chromosomal location and population dynamics. Proc. Natl. Acad. Sci. 81:8014-8018.

Sambrook, J., E.F. Fritsch, and T. Maniatis. 1989. Molecular cloning: A laboratory manual. Cold Spring Harbor Laboratory Press, Cold Spring Harbor, N.Y.

Sweeney, P.M. and T.K. Danneberger. 1994. Random amplified polymorphic DNA in perennial ryegrass: A comparison of bulk samples versus individuals. HortScience 29:624-626.

Sweeney, P.M., R.C. Golembiewski, and T.K. Danneberger. 1996. Random amplified polymorphic DNA analysis of dry turfgrass seed. HortScience 31:400-401.

Williams, J.G.K., A.R. Kubelik, K.J. Livak, J.K. Rafalski, and S.V. Tingey. 1990. DNA polymorphisms amplified by arbitrary primers are useful as genetic markers. Nucleic Acids Res. 18:6531-6535. 